\title{
Erratum to: Dissolution Similarity Requirements: How Similar or Dissimilar Are the Global Regulatory Expectations?
}

\author{
Dorys Argelia Diaz, ${ }^{1,4}$ Stephen T. Colgan, ${ }^{1}$ Connie S. Langer, ${ }^{1}$ Nagesh Bandi, ${ }^{2}$ \\ Michael D. Likar, ${ }^{3}$ and Leslie Van Alstine ${ }^{3}$
}

Published online 4 November 2015

\section{Erratum to: AAPS J}

DOI 10.1208/s12248-015-9830-9

An author name was inadvertently misrepresented. The correct author list is as follows:

Dorys Argelia Diaz, Stephen T. Colgan, Connie S. Langer, Nagesh Bandi, Michael D. Likar, Leslie Van Alstine

The online version of the original article can be found at http:// dx.doi.org/10.1208/s12248-015-9830-9.

\footnotetext{
${ }^{1}$ Worldwide Research and Development, Global Chemistry and Manufacturing Controls, Pfizer Inc, Eastern Point Road, Groton, Connecticut 06340, USA.

${ }^{2}$ Worldwide Research and Development, Global Chemistry and Manufacturing Controls, Pfizer Inc, 100 Route 206 North, Peapack, New Jersey 07977, USA.

${ }^{3}$ Worldwide Research and Development, Analytical Research and Development, Pfizer Inc, Eastern Point Road, Groton, Connecticut 06340, USA.

${ }^{4}$ To whom correspondence should be addressed. (e-mail: dorys.argelia.diaz@pfizer.com)
} 